\title{
PEPTAIBOL PROFILES OF IRANIAN TRICHODERMA ISOLATES
}

\author{
PARisa RAhimi TAMANDEgani, ${ }^{1}$ Doustmorad ZAFAri, ${ }^{1 *}$ TAMÁs MARIK, ${ }^{2}$

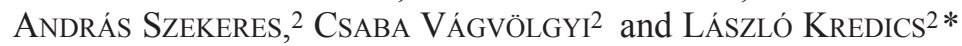 \\ ${ }^{1}$ Department of Plant Protection, Bu Ali Sina University, Hamedan, Iran \\ ${ }^{2}$ Department of Microbiology, Faculty of Science and Informatics, University of Szeged, \\ Szeged, Hungary
}

(Received: July 02, 2016; accepted: July 28, 2016)

\begin{abstract}
Five Iranian Trichoderma isolates from species T. viride, T. viridescens, T. asperellum, T. longibrachiatum and T. citrinoviride - selected from the Fungal Collection of the Bu Ali Sina University, Hamedan, Iran - were investigated for their peptaibol production. All examined isolates showed remarkable antibacterial activities during the screening of their extracts for peptaibol content with a Micrococcus luteus test culture. HPLC-ESI-IT MS was used for identification and elucidation of the amino acid sequences of peptaibols. The detected peptaibol compounds contain 20 or 18 amino acid residues and belong to the trichobrachin and trichotoxin groups of peptaibols, respectively. T. longibrachiatum and T. citrinoviride produced trichobrachins, while trichotoxins could be detected in T. viride, T. viridescens and T. asperellum. Out of 37 sequences detetermined, 26 proved to be new, yet undescribed compounds, while others were identified as previously reported trichotoxins (trichotoxin A-50s and T5D2) and trichobrachins (longibrachins AI, AII, AIII, BII and BIII). Compounds within the two groups of detected peptaibols differed from each other only by a single or just a few amino acid changes.
\end{abstract}

Keywords: Trichoderma - peptaibol - antimicrobial activity - high performance liquid chromatography - electrospray ionization mass spectrometry

\section{INTRODUCTION}

The genus Trichoderma was described in 1794 by Persoon [37]. It is a worldwide distributed soil saprophytic fungal genus, the representatives of which have been used as biological control agents against various fungal pathogens. The first report about the biocontrol potential of Trichoderma was published by Weindling [47]. Presently, about $60 \%$ of all registered biofungicides worldwide are Trichoderma-based products [44]. These fungi can adapt to different ecological environments [17] and are mycoparasites [21], antibiotic producers [38], plant growth promoters, metabolizers of xenobiotics [18], plant disease control agents and commercial biofungicides [11]. Some species of this genus are clinically important (e.g. T. longibrachiatum and T. citrinoviride [13]) or harmful in the mushroom industry (e.g. T. aggressivum [16]), while others are used for the bioremediation of organic and inorganic wastes includ-

*Corresponding authors; e-mail addresses: zafari_d@yahoo.com, kredics@bio.u-szeged.hu 
ing heavy metals $[10,11,15]$. Trichoderma species can confer biotic and abiotic stress tolerance [21], and control fungi belonging to taxonomically diverse groups as well as oomycetes [31]. They also restrict pathogenic bacterial growth on foliage [12] and parasitize nematodes [42].

Trichoderma species are rich sources of different secondary metabolites (SMs), some of which have antimicrobial activities [45]. They produce a wide range of SMs that can affect phytopahogens directly or change plant metabolism to induce resistance or promote plant growth [46]. The production of SMs correlates with the different stages of morphological development [6]. Pyrones, koninginins, viridins, nitrogen heterocyclic compounds, azaphilones, butenolides and hydroxy-lactones, diketopiperazines, isocyano metabolites and peptaibols are secondary metabolites known to be toxic to many fungi [46].

Peptaibols form a class of antibiotics that act as microbe-associated molecular patterns and elicitors, and also can trigger the plant defense responses against pathogens. These short linear, $\alpha$-helical peptides of 5-20 residues can be characterized with $\alpha$-aminoisobutyric acid-rich content, an acetylated $\mathrm{N}$-terminus and a $\mathrm{C}$-terminal amino alcohol (e.g. phenylalaninol, valinol, leucinol, isoleucinol or tryptophanol). They contain high amount of non-proteinogenic amino acids (e.g. $\alpha$-aminoisobutyric acid and isovaline) [43]. According to the sequence alignment and special amino acid composition, peptaibols have been classified into 9 subfamilies (SF1 to SF9) [7]. Members of SF1, 4, 5 and 9 are produced by Trichoderma species [30].

Alamethicin is the firstly characterized peptaibol, isolated from the culture broth of Trichoderma viride [26,33], however, the producer strain was later re-identified as T. arundinaceum [20]. This peptide was shown to react with the cell membrane in target cells [29]. U-22324F was the first name of this compound but later its name was changed to alamethicin [20].

Peptaibols are synthesized by multifunctional non-ribosomal peptide synthetases (NRPs), e.g. texl, tex2 and tex3 [30,50], which have modular structures where each single module is adding a single residue to the final peptide [22]. A minimum unit of a NRPS contains adenylation (A), thiolation (T) and condensation (C) domains [40].

Peptaibols have antifungal, antibacterial, antiviral and anticancer activities [9]. The biological activities of alamethicin on oysters (Crassostrea gigas), as well as of tetrodotoxin, saxitoxin and longibrachin on Diptera larvae are also known from the literature [36].

Online protein databases such as PDB (www.rcsb.org/pdb/home/home.do) and UniProt (www.uniprot.org) do not contain peptaibol sequences because of their special characteristics such as unusual amino acids, short lengths and absence of genetically coded sequences [32, 49]. In 1997 the first online peptaibol database containing 9 subfamilies of peptaibols was released [39]. Whitmore et al. [48] gathered more than 300 peptaibols in a freely accessible database at http://peptaibol.cryst.bbk.ac.uk/ home.shtml containing sequence, structure, biological source, crystallography data, groupings of sequences, specified sequence motifs and some other information [48] and in 2004 updated it [49]. In 2013, Stoppacher et al. [39] constructed "The comprehensive peptaibiotics database" containing information of 1062 Aib-containing non- 
ribosomal fungal peptides. This database was originally a downloadable software tool based on Microsoft (MS) Access, but it was later developed to an online resource available at peptaibiotics-database.boku.ac.at [49]. Till 2015, 235 new peptaibol sequences were added to this database [32].

In this study we present the sequences of 18- and 20-residue peptaibols detected in Trichoderma strains isolated from Iranian soil samples.

\section{MATERIALS AND METHODS}

\section{Strains, culture conditions and extraction procedures}

Isolates from the species T. viride, T. viridescens, T. asperellum, T. longibrachiatum and $T$. citrinoviride deriving from the $\mathrm{Bu}$ Ali Sina University Fungal Collection (BASUFC), Hamedan, Iran were examined during this study (Table 1). The strains were previously isolated from soil samples collected in different regions of Iran and after purification by the hyphal tip method they were identified by morphological characteristics and the sequence analysis of their internal transcribed spacer (ITS) region using the online software TrichOkey 2.0 (www.isth.info). Fungal strains were cultured on malt extract agar (MEA: $5 \mathrm{~g} \mathrm{l}^{-1}$ malt extract, $2.5 \mathrm{~g} \mathrm{l}^{-1}$ yeast extract, $10 \mathrm{~g} \mathrm{l}^{-1}$ glucose and $20 \mathrm{~g} \mathrm{l}^{-1}$ agar) before extraction.

Preparation of crude extracts from the cultures was performed according to Marik et al. [23]. Screening of extracts for peptaibol content was carried out with Micrococcus luteus test culture SZMC 0264 as described by Marik et al. [24]. The bioactive crude extracts were fractionated by solid phase extraction on Silica gel 60 $(0.015-0.040 \mathrm{~mm})$ with methanol/chloroform mixtures as mobile phase. Conditioning was performed by washing the cartridge with $3 \mathrm{ml}$ methanol and $3 \mathrm{ml}$ chloroform. The $3 \mathrm{ml}$ chloroform was added to the stored dry extract and passed with vacuum using a 12 port Visiprep SPE manifold (Supelco, USA) through a conditioned cartridge. Stepwise elution was performed with $3 \mathrm{ml}$ portions of methanol/chloroform successively from $0 \%$ to $100 \%$ methanol in 11 steps. The effluents were collected into clean tubes and evaporated to dryness using nitrogen. Then $200 \mu 1$ methanol was added to each tube and kept at $-20{ }^{\circ} \mathrm{C}$ for further analyzes. The efficiency of the SPE procedure was tested with the bioassay screening procedure on Micrococcus luteus as described above [24].

Table 1

Trichoderma strains involved in the study

\begin{tabular}{|l|c|l|c|}
\hline \multicolumn{1}{|c|}{ Species } & \multicolumn{1}{|c|}{$\begin{array}{c}\text { BASUFC culture } \\
\text { collection number }\end{array}$} & \multicolumn{1}{c|}{ Geographic location } & Source of isolation \\
\hline T. viride & 06886H & Iran, Hamedan & Soil \\
T. viridescens & 06768A & Iran, Hamedan & Rhizosphere of potato \\
T. asperellum & 06256F & Iran, Kordistan & Rhizosphere of potato \\
T. citrinoviride & 06758A & Iran, Guilan & Soil \\
T. longibrachiatum & 06983B & Iran, Markazi & Soil \\
\hline
\end{tabular}

BASUFC: Bu Ali Sinai University Fungal Collection, Hamedan, Iran. 


\section{High performance liquid chromatography - ion trap mass spectrometry}

Reversed phase high performance liquid chromatography (HPLC) - electrospray ionization (ESI) - mass spectrometry (MS) was carried out on an Agilent 1100 modular HPLC system (Palo Alto, USA) coupled to Varian 500 ion trap (IT) MS (Agilent, USA) as described by Marik et al. [25]. The sequence of y ions originating from the split of the labile Aib-Pro bond in MS full scan mode were predicted by calculations based on the sequences with identical masses found in the Comprehensive Peptaibiotics Database and b-ion series sequence homologies [39].

The newly described peptaibols were designated with individual identifiers. Names of the compounds were generated from 3 characteristic parts of the molecules with a "Pept" prefix followed by the molecular mass (first number), the type of the C-terminal part from the Aib-Pro residues (second alphabetic character) and the elution order in our separation system (third number). For the sequences the three letter amino acid codes were used and supplemented with "ol" ending in the case of amino alcohol residues. The C-terminal parts (major y ion sequence) predicted in this study were the following: -Pro-Lxx-Aib-Aib-Gln-Vxxol (a), -Pro-LxxAib-Vxx-Gln-Vxxol (b), -Pro-Vxx-Aib-Vxx-Gln-Gln-Pheol (c) and -Pro-Vxx-AibVxx-Glu-Gln-Pheol (d). The nomenclature for fragment ions observed on the MS ${ }^{1}$ spectra followed the terminology published by Biemann [1] as well as by Roepstorff and Fohlman [35].

\section{RESULTS}

\section{Antibacterial activity of crude extracts and SPE fractions of Iranian Trichoderma isolates}

All examined isolates showed remarkable antibacterial activities. The largest inhibition zone (22 $\mathrm{mm}$ in diameter) was around the crude extract of T. asperellum, while the least effective inhibition with an inhibition zone of $9 \mathrm{~mm}$ in diameter occurred around T. citrinoviride. Alamethicin equivalent concentrations [24] of the crude extracts were $541.64,635.59,635.59,150.65$ and $79.45 \mu \mathrm{g} / \mathrm{ml}$ for $T$. viride, $T$. viridescens, T. asperellum, T. longibrachiatum and T. citrinoviride, respectively. Bioassays were also performed with the SPE fractions, then the active fractions were pooled for each isolate and subjected to HPLC-IT-MS measurements.

\section{Mass spectrometric analysis of peptaibols detected from Iranian Trichoderma isolates}

Singly and double charged sodium adducts of the peptaibols were formed in the ESI source and could be easily identified on the MS spectra, which determined the molecular masses of the molecules (Fig. 1). The fragmentation of peptides already occurred 

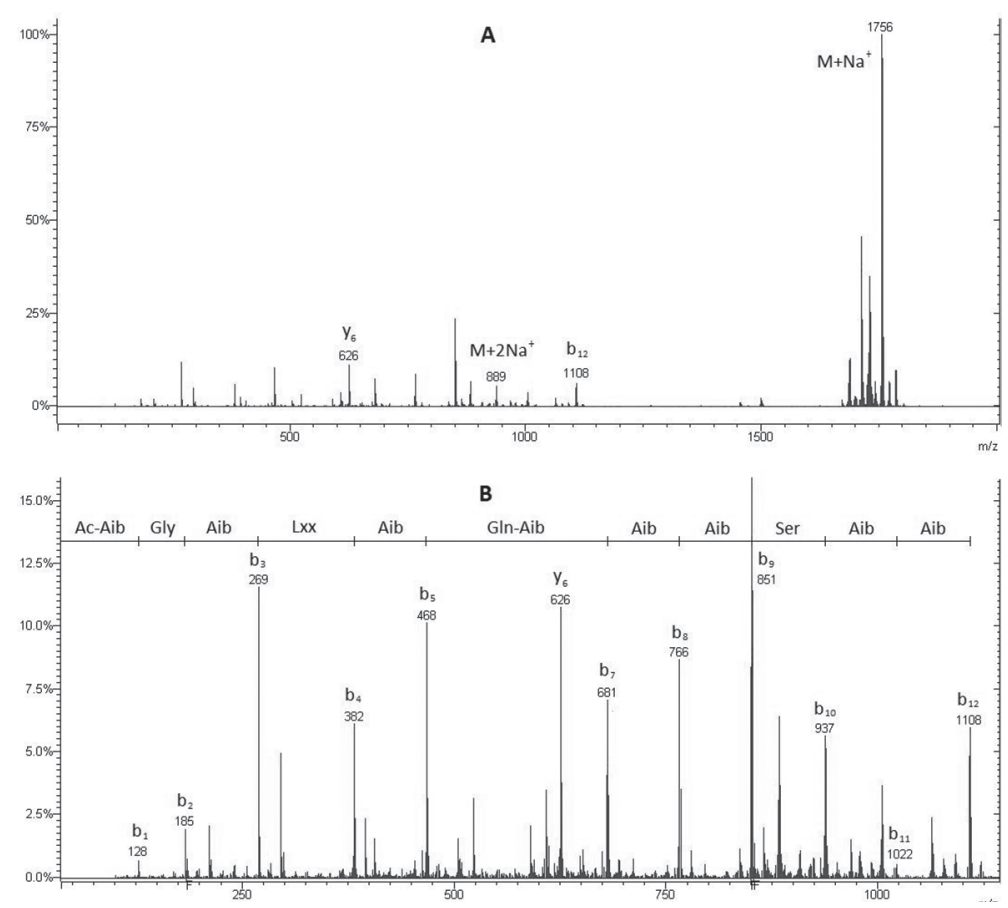

Fig. 1. Full scan mass spectrum of compound Pept-1733-b-2 investigated by HPLC-ESI-MS. A: Full range MS spectrum with marked characteristic ions, $\mathrm{B}$ : enlarged region of the b-series ions with the amino acid residues

between the labile Aib-Pro bonds forming the major y ions $\mathrm{y}_{6}$ and $\mathrm{y}_{7}$ for 18- and 20-residue peptaibols, respectively, as well as the series of b ions (Fig. 1A). The b series ions of the N-terminal peptide parts were clearly detected on the MS spectra (Fig. 1B). For both the 18- and 20-residue peptaibols, two types of y-ions containing $6(\mathrm{~m} / \mathrm{z} 612$ and 626) and $7(\mathrm{~m} / \mathrm{z} 770$ and 790$)$ amino acids were predicted. The initial part of the sequences showed high similarities between the detected peptaibol molecules, which was followed by variable inner residues involving the Gln-Aib residue pairs at the 6-7 and 7-8 positions in the case of 18- and 20-residue peptaibols, respectively.

Full scan mass spectra of the crude extracts showed that $T$. longibrachiatum and T. citrinoviride produced 20-residue peptaibols, while 18-residue peptaibols could be detected in $T$. viride, $T$. viridescens and T. asperellum (Table 2). The results revealed the following numbers of compounds: T. asperellum 06256F: 26, T. viridescens 06768A: 26, T. viride 06886H: 27, T. citrinoviride 06758A: 10, and T. longibrachiatum 06983B: 10 .

In the case of $T$. viride, $T$. viridescens and $T$. asperellum, 18-residue trichotoxins were detected, most of which were produced by all three isolates. However, compounds Pept-1705-a-3 and Pept-1733-b-1 were not detected from T. viridescens and 


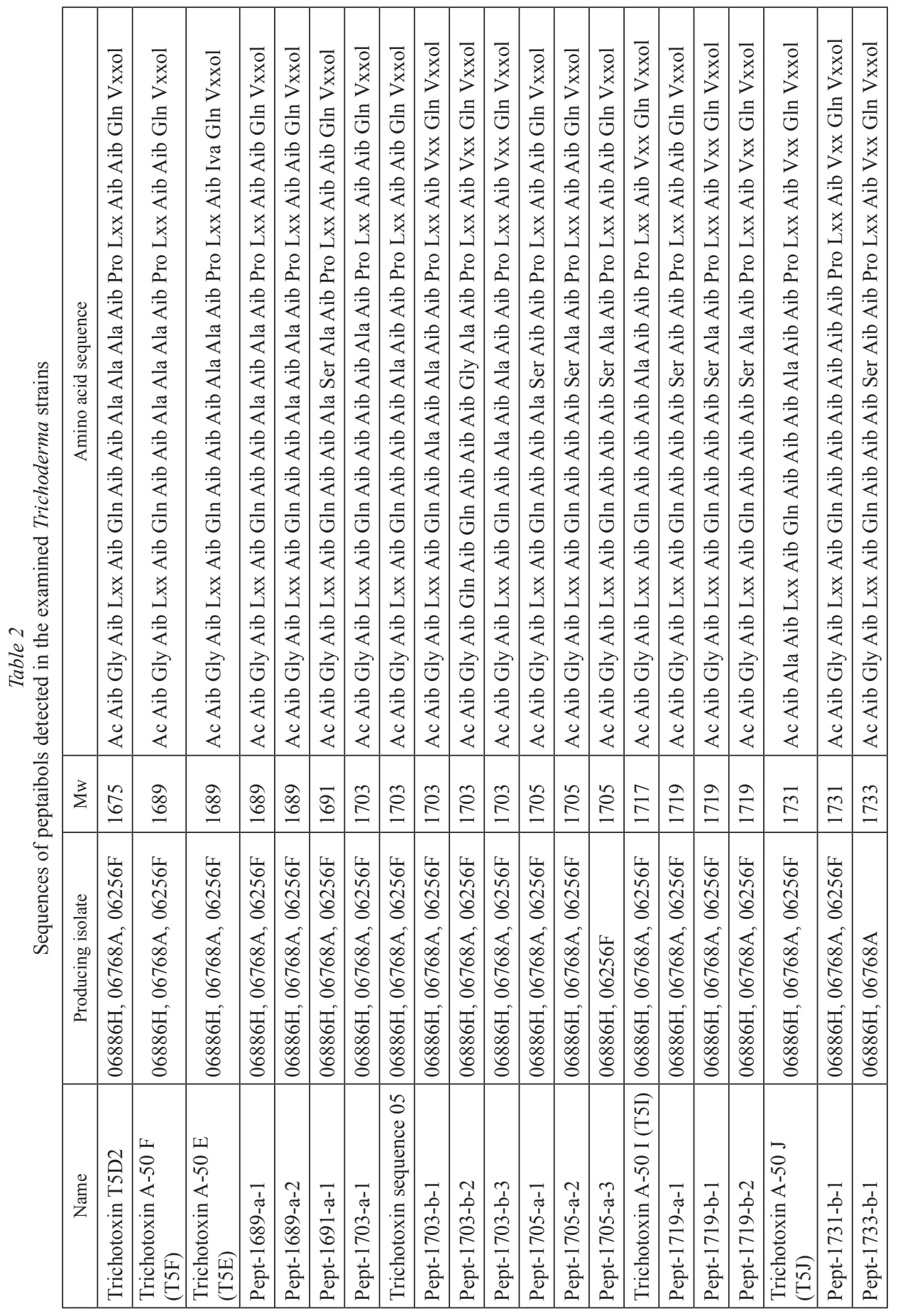




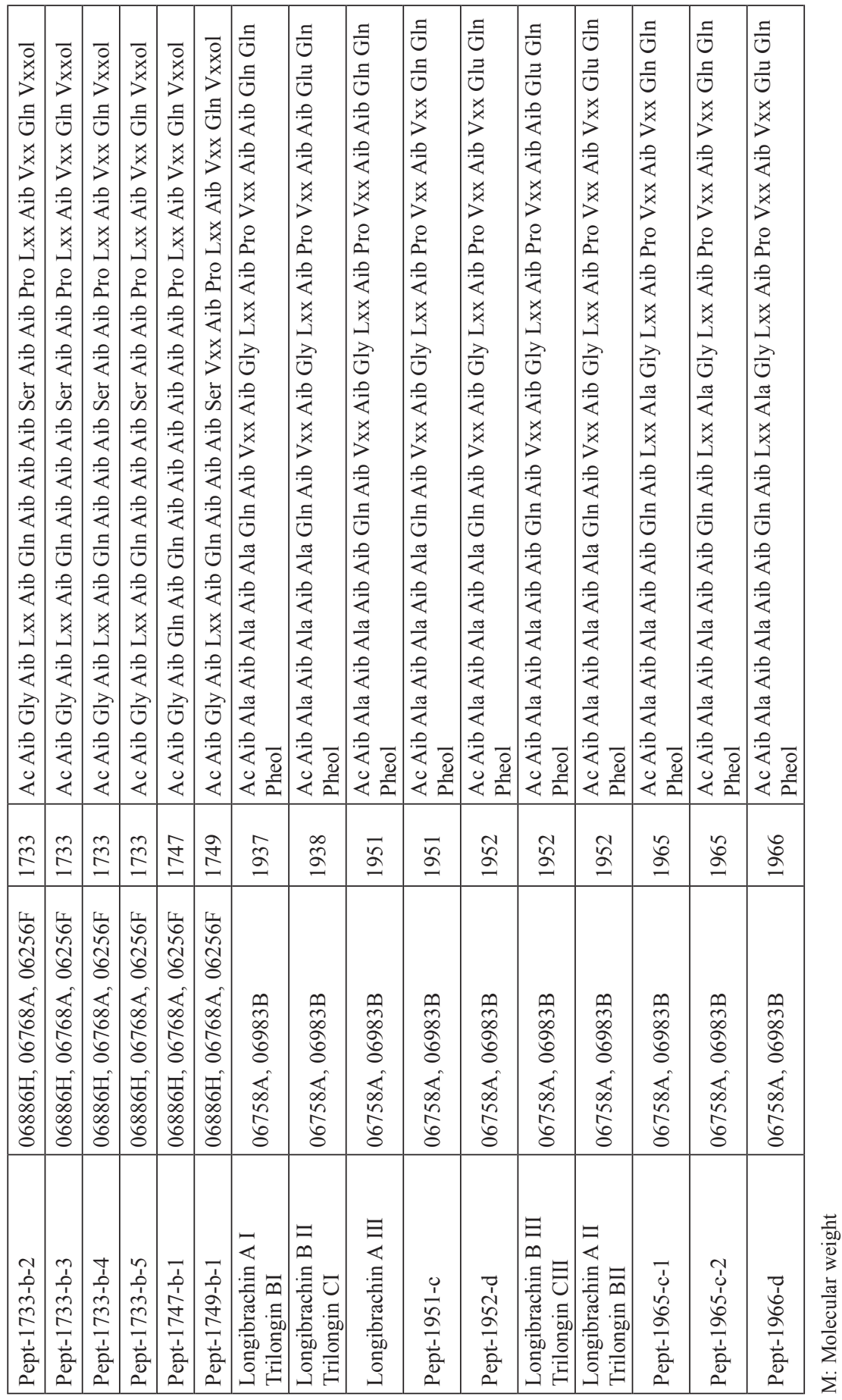


T. asperellum, respectively. Twenty-residue, trichobrachin-like peptaibols were produced by the isolates belonging to the two clinically most relevant species of the genus, T. longibraciatum and T. citrinoviride, which could be characterized by completely identical peptaibol profiles.

\section{DISCUSSION}

The toxic effects of peptaibols are reliable properties during their detection. Results of the bioassay tests on Bacillus subtilis, Escherichia coli, M. luteus and Serratia marcescens showed that the largest inhibition zones of methanolic crude extracts deriving from Trichoderma species were detected in the case of M. luteus [24], therefore the optimized screening method based on this bacterium was applied during the present study. The bioassay revealed that all examined isolates of $T$. viride, $T$. viridescens, T. asperellum, T. citrinoviride and T. longibrachiatum have bioactive compounds in their crude extracts.

Peptaibols have the same chemical characteristics and molecular masses, therefore they cannot be completely separated by HPLC and are eluted together [28]. The complete separation of peptaibols is usually difficult but certain methods such as high energy collision, or collision-induced dissociation mass spectrometry were applicable to characterize peptaibols in crude extracts [34]. The ESI-IT-MS technology is a more simple method for the sequencing of peptaibols [28]. We used HPLC for separation and ESI-MS for sequencing and identification of peptaibol compounds. ESI-MS produced pseudomolecular ions such as $[\mathrm{M}+\mathrm{H}]^{+},[\mathrm{M}+\mathrm{Na}]^{+},[\mathrm{M}+\mathrm{K}]^{+},[2 \mathrm{M}+\mathrm{H}]^{+}$and $[\mathrm{M}+2 \mathrm{Na}]^{+}$or $[\mathrm{M}-\mathrm{H}]^{-}$in negative-mode. An advantage of this method is that only small samples are needed $[9,25]$.

Two groups of peptaibols were detected in the examined isolates: 18-residue peptaibols from T. viride, T. viridescens and T. asperellum, and 20-residue peptaibols from $T$. citrinoviride and T. longibrachiatum. The separated peptaibols are sequence analogues of 18-residue trichotoxins and 20-residue trichobrachins. Compounds within the two groups differed from each other only by single or few amino acid changes.

Trichotoxins were shown already in the early studies to induce voltage-dependent pores in bilayer lipid membranes [2]. Some of the compounds detected in this study were similar to peptaibol sequences available in the Comprehensive Peptaibiotics Database [39] as trichotoxin A-50 E (T5E), A-50 F (T5F), A-50 I (T5I) and A-50 J (T5J) [5] as well as trichotoxin T5D2 and trichotoxin sequence 05 [41]. We also found 21 yet undescribed trichotoxin sequences obtained as microheterogeneous mixtures produced by members of the Viride clade. Besides T. viride [4, 5, 14], the production of trichotoxins was also reported in the literature for T. asperellum (clade Hamatum [3, 8]) and T. harzianum (clade Harzianum [41]), suggesting that this group of peptaibols can be produced by various subtaxa within the genus Trichoderma. Our results are in agreement with these previous data by confirming the trichotoxin production ability of further $T$. asperellum and $T$. viride isolates, and in addition they 
reveal the production of trichotoxins also in the case of $T$. viridescens from clade Viride.

Longibrachins [19] and trilongins [27] are belonging to the group of trichobrachins with high similarities to the T. citrinoviride and T. longibrachiatum sequences presented in Table 2. Some of the compounds detected in this study were similar to known sequences including Longibrachin AI (Trilongin BI), BII (Trilongin CI), AIII, BIII (Trilongin CIII) and AII (Trilongin BII) [39]. Five yet undescribed longibrachinrelated sequences were also detected in both Iranian isolates. In a recent study, similar compounds were reported from forest-derived isolates of T. aethiopicum, T. novaezelandiae and T. pseudokoningii from section Longibrachiatum of the genus [23].

The recent study is the first attempt to detect peptaibols from Iranian Trichoderma isolates. Members of Trichoderma section Longibrachiatum were producing entirely different peptaibols than members of sections Viride and Hamatum. Further studies are needed to clear the role of the individual compounds in the producer Trichoderma species.

\section{ACKNOWLEDGEMENTS}

This work was supported by grants NKFI K-105972 (National Research, Development and Innovation Office, Hungary) and GINOP-2.3.3-15-2016-00006 (Széchenyi 2020 Programme, Hungary).

\section{REFERENCES}

1. Biemann, K. (1990) Sequencing of peptides by tandem mass spectrometry and high-energy collisioninduced dissociation. Methods Enzymol. 193, 455-479.

2. Boheim, G., Irmscher, G., Jung, G. (1978) Trichotoxin A-40, a new membrane-exciting peptide. Part B. Voltage-dependent pore formation in bilayer lipid membranes and comparison with other alamethicin analogues. Biochim. Biophys. Acta-Biomem. 507, 485-506.

3. Brito, J. P., Ramada, M. H., de Magalhães, M. T., Silva, L. P., Ulhoa, C. J. (2014) Peptaibols from Trichoderma asperellum TR356 strain isolated from Brazilian soil. SpringerPlus 3, 600.

4. Brückner, H., König, W. A., Aydin, M, J. G. (1985) Trichotoxin A40. Purification by counter-current distribution and sequencing of isolated fragments. Biochim. Biophys. Acta 827, 51-62.

5. Brückner, H., Przybylski, M. (1984) Isolation and structural characterization of polypeptide antibiotics of the peptaibol class by high-performance liquid chromatography with field desorption and fast atom bombardment mass spectrometry. J. Chromatogr. 296, 263-275.

6. Chiang, Y. M., Lee, K. H., Sanchez, J. F., Keller, N. P., Wang, C. C. (2009) Unlocking fungal cryptic natural products. Nat. Prod. Commun. 4, 1505-1510.

7. Chugh, J. K., Wallace, B. A. (2001) Peptaibols: models for ion channels. Biochem. Soc. Trans. 29, 565 .

8. Chutrakul, C., Alcocer, M., Bailey, K., Peberdy, J. F. (2008) The production and characterisation of trichotoxin peptaibols, by Trichoderma asperellum. Chem. Biodivers. 5, 1694-1706.

9. Degenkolb, T., Brückner, H. (2008) Peptaibiomics: towards a myriad of bioactive peptides containing C(alpha)-dialkylamino acids? Chem. Biodivers. 5, 1817-1843.

10. Grodnitskaya, I. D., Sorokin, N. D. (2006) Use of micromycetes Trichoderma for soil bioremediation in tree nurseries. Biol. Bull. 33, 400-403.

11. Ha, T. (2010) Using Trichoderma species for biological control of plant pathogens in Vietnam. ISSAAS J. 16, 17-21. 
12. Harman, G. E., Howell, C. R., Viterbo, A., Chet, I., Lorito, M. (2004) Trichoderma species - opportunistic, avirulent plant symbionts. Nat. Rev. Microbiol. 2, 43-56.

13. Hatvani, L., Manczinger, L., Vágvölgyi, C., Kredics, L. (2013) Trichoderma as a human pathogen. In: Mukherjee, P. K., Horwitz, B. A., Singh, U. S., Mukherjee, M., Schmoll, M. (eds) Trichoderma Biology and Applications. CAB International, Wallingford, UK. pp. 292-313.

14. Hou, C. T., Ciegler, A., Hesseltine, C. W. (1972) New mycotoxin, trichotoxin A, from Trichoderma viride isolated from southern leaf blight-infected corn. Appl. Microbiol. 23, 183-185.

15. Kredics, L., Antal, Z., Manczinger, L., Nagy, E. (2001) Breeding of mycoparasitic Trichoderma strains for heavy metal resistance. Lett. Appl. Microbiol. 33, 112-116.

16. Kredics, L., García Jimenez, L., Naeimi, S., Czifra, D., Urbán, P., Manczinger, L., Vágvölgyi, C., Hatvani, L. (2010) A challenge to mushroom growers: the green mould disease of cultivated champignons. In: Méndez-Vilas, A. (ed.) Current Research, Technology and Education Topics in Applied Microbiology and Microbial Biotechnology. Formatex Research Center, Badajoz, Spain. pp. 295-305.

17. Kredics, L., Hatvani, L., Naeimi, S., Körmöczi, P., Manczinger, L., Vágvölgyi, C., Druzhinina, I. (2014) Biodiversity of the genus Hypocrea/Trichoderma in different habitats. In: Gupta, V. K., Schmoll, M., Herrera-Estrella, A., Upadhyay, R. S., Druzhinina, I., Tuohy, M. (eds) Biotechnology and Biology of Trichoderma. Elsevier Science B. V., Amsterdam, The Netherlands. pp. 3-24.

18. Kubicek, C. P., Komon-Zelazowska, M., Sándor, E., Druzhinina, I. S. (2007) Facts and challenges in the understanding of the biosynthesis of peptaibols by Trichoderma. Chem. Biodivers. 4, 1068-1082.

19. Leclerc, G., Goulard, C., Prigent, Y., Bodo, B., Wróblewski, H., Rebuffat, S. (2001) Sequences and antimycoplasmic properties of longibrachins LGB II and LGB III, two novel 20-residue peptaibols from Trichoderma longibrachiatum. J. Nat. Prod. 64, 164-170.

20. Leitgeb, B., Szekeres, A., Manczinger, L., Vágvölgyi, C., Kredics, L. (2007) The history of alamethicin: a review of the most extensively studied peptaibol. Chem. Biodivers. 4, 1027-1051.

21. Lorito, M., Woo, S. L., Garcia, I., Colucci, G., Harman, G. E., Pintor-Toro, J. A., Scala, F. (1998) Genes from mycoparasitic fungi as a source for improving plant resistance to fungal pathogens. Proc. Natl Acad. Sci. USA 95, 7860-7865.

22. Marahiel, M. A., Stachelhaus T., Mootz, H. D. (1997) Modular peptide synthetases involved in nonribosomal peptide synthesis. Chem. Rev. 97, 2651-2674.

23. Marik, T., Szekeres, A., Druzhinina, I. S., Andersson, M. A., Salkinoja-Salonen, M., Tyagi, C., Leitgeb, B., Vágvölgyi, C., Kredics, L. (2016) Bioactive peptaibols of forest-derived Trichoderma isolates from section Longibrachiatum. In: Lukac, M., Grenni, P., Gamboni, M. (eds) Soil Biological Communities and Ecosystem Resilience, "Sustainability in Plant and Crop Protection", Springer Int. Publ. AG, Cham (WWW), Switzerland (in press).

24. Marik, T., Szekeres, A., Várszegi, C., Czifra, D., Vágvölgyi, C., Kredics, L. (2013) Rapid bioactivitybased pre-screening method for the detection of peptaibiotic-producing Trichoderma strains. Acta Biol. Szeged 57, 1-7.

25. Marik, T., Várszegi, C., Kredics, L., Vágvölgyi, C., Szekeres, A. (2013) Mass spectrometric investigation of alamethicin. Acta Biol. Szeged. 57, 109-112.

26. Meyer, C. E., Reusser, F. (1967) A polypeptide antibacterial agent isolated from Trichoderma viride. Experientia 23, 85-86.

27. Mikkola, R., Andersson, M. A., Kredics, L., Grigoriev, P. A., Sundell, N., Salkinoja-Salonen, M. S. (2012) 20-Residue and 11-residue peptaibols from the fungus Trichoderma longibrachiatum are synergistic in forming $\mathrm{Na}^{+} / \mathrm{K}^{+}$-permeable channels and adverse action towards mammalian cells. FEBS J. 279, 4172-4190.

28. Mohamed-Benkada, M., Montagu, M., Biard, J. F., Mondeguer, F., Verite, P., Dalgalarrondo, M., Bissett, J., Pouchus, Y. F. (2006) New short peptaibols from a marine Trichoderma strain. Rapid Commun. Mass Spectrom. 20, 1176-1180.

29. Mueller, P., Rudin, D. O. (1968) Action potentials induced in biomolecular lipid membranes. Nature 217, 713-719. 
30. Mukherjee, P. K., Wiest, A., Ruiz, N., Keightley, A., Moran-Diez, M. E., McCluskey, K., Pouchus, Y. F., Kenerley, C. M. (2010) Two classes of new peptaibols are synthesized by a single non-ribosomal peptide synthetase of Trichoderma virens. J. Biol. Chem. 286, 4544-4554.

31. Nelson, E. B. (2004) Biological control of Oomycetes and fungal pathogens. In: Goodman, R. M. (ed.) Encyclopedia of Plant and Crop Science. Marcell Dekker Inc., New York, USA. pp. 137-140.

32. Neumann, N. K. N., Stoppacher, N., Zeilinger, S., Degenkolb, T., Brückner, H., Schuhmacher, R. (2015) The peptaibiotics database - a comprehensive online resource. Chem. Biodivers. 12, 743-751.

33. Payne, J. W., Jakes, R., Hartley, B. S. (1970) The primary structure of alamethicin. Biochem. J. 117, 757-766.

34. Pócsfalvi, G., Ritieni, A., Ferranti, P., Randazzo, G., Vékey, K., Malorni, A. (1997) Microheterogeneity characterization of a paracelsin mixture from Trichoderma reesei using high-energy collision-induced dissociation tandem mass spectrometry. Rapid Commun. Mass Spectrom. 11, 922-930.

35. Roepstorff, P., Fohlman, J. (1984) Proposal for a common nomenclature for sequence ions in mass spectra of peptides. Biomed. Mass. Spectrom. 11, 601.

36. Ruiz, N., Petit, K., Vansteelandt, M., Kerzaon, I., Baudet, J., Amzil, Z., Biard, J.-F., Grovel, O., Pouchus, Y. F. (2010) Enhancement of domoic acid neurotoxicity on Diptera larvae bioassay by marine fungal metabolites. Toxicon 55, 805-810.

37. Schmoll, M., Schuster, A. (2010) Biology and biotechnology of Trichoderma. Appl. Microbiol. Biotechnol. 87, 787-799.

38. Shakeri, J., Foster, H. (2007) Proteolytic activity and antibiotic production by Trichoderma harzianum in relation to pathogenicity to insects. Enzyme Microb. Technol. 40, 961-968.

39. Stoppacher, N., Neumann, N. K., Burgstaller, L., Zeilinger, S., Degenkolb, T., Brückner, H., Schuhmacher, R. (2013) The comprehensive peptaibiotics database. Chem. Biodivers. 10, 734-743.

40. Strieker, M., Tanović, A., Marahiel, M. A. (2010) Nonribosomal peptide synthetases: structures and dynamics. Curr. Opin. Struct. Biol. 20, 234-240.

41. Suwan, S., Isobe, M., Kanokmedhakul, S., Lourit, N., Kanokmedhakul, K., Soytong, K., Koga, K. (2000) Elucidation of high micro-heterogeneity of an acidic-neutral trichotoxin mixture from Trichoderma harzianum by electrospray ionization quadrupole time-of-flight mass spectrometry. J. Mass Spectrom. 35, 1438-1451.

42. Szabó, M., Csepregi, K., Gálber, M., Virányi, F., Fekete, C. (2012) Control plant-parasitic nematodes with Trichoderma species and nematode-trapping fungi: The role of chi18-5 and chi18-12 genes in nematode egg-parasitism. Biol. Control 63, 121-128.

43. Szekeres, A., Leitgeb, B., Kredics, L., Antal, Z, Hatvani, L., Manczinger, L., Vágvölgyi, C. (2005) Peptaibols and related peptaibiotics of Trichoderma - a review. Acta Microbiol. Immunol. Hung. 52, $137-168$.

44. Verma, V. C., Gond, S. K., Kumar, A., Kharwar, R. N., Strobel, G. (2007) The endophytic mycoflora of bark, leaf, and stem tissues of Azadirachta indica A. Juss (neem) from Varanasi (India). Microb. Ecol. 54, 119-125.

45. Vinale, F., Sivasithamparam, K. E. A. (2012) Trichoderma secondary metabolites that affect plant metabolism. Nat. Prod. Commun. 7, 1545-1550.

46. Vinale, F., Sivasithamparam, K., Ghisalberti, E. L., Woo, S. L., Nigro, M., Marra, R., Lombardi, N., Pascale, A., Ruocco, M., Lanzuise, S., Manganiello, G., Lorito, M. (2014) Trichoderma secondary metabolites active on plants and fungal pathogens. Open Mycol. J. 8, 127-139.

47. Weindling, R. (1932) Trichoderma lignorum as a parasite of other soil fungi. Phytopathology 22, $837-845$.

48. Whitmore, L., Chugh, J. K., Snook, C. F., Wallace, B. A. (2003) The peptaibol database: a sequence and structure resource. J. Pept. Sci. 9, 663-665.

49. Whitmore, L., Wallace, B. A. (2004) The peptaibol database: a database for sequences and structures of naturally occurring peptaibols. Nucl. Acids Res. 32, D593-D594.

50. Wiest, A., Grzegorski, D., Xu, B.-W., Goulard, C., Rebuffat, S., Ebbole, D. J., Bodo, B., Kenerley, C. (2002) Identification of peptaibols from Trichoderma virens and cloning of a peptaibol synthetase. J. Biol. Chem. 277, 20862-20868. 